\title{
Birch Pollen IgE Measurement
}

National Cancer Institute

\section{Source}

National Cancer Institute. Birch Pollen IgE Measurement. NCI Thesaurus. Code C130072.

A measurement of the birch pollen IgE in a biological specimen. 